\title{
Lo que nos puede traer la pandemia
}

\section{What can bring us the pandemic}

La epidemia de Covid-19, declarada el 11 de marzo de 2020 por la Organización Mundial de la Salud (OMS), como una nueva pandemia mundial (1), está generando un impacto sin precedentes en la salud, en la economía y social en los países y en el mundo.

El primer caso en Latinoamérica se registró en Brasil el 26 de febrero y el primer caso en Perú, el 06 de marzo. El 11 de marzo, se declara el estado de Emergencia sanitaria a nivel nacional por 90 días y dispone de medidas de prevención y control para evitar la propagación del COVID-19, entre ellas, la postergación del inicio o suspensión de las actividades en los centros educativos en todos los niveles (2). El domingo 15 de marzo, el gobierno peruano declara el estado de Emergencia Nacional por 15 días calendario, y dispone el aislamiento social obligatorio (cuarentena), limitación en el libre tránsito y el cierre de fronteras (3).

Hace 29 años en el Perú ocurrió una situación similar, fue azotado por la epidemia de cólera; los primeros casos ocurrieron casi simultáneamente en tres ciudades costeras separadas entre sí, Chancay, Chimbote y Piura. De allí el mal se diseminó a otras áreas urbanas y rurales del Perú, inicialmente por toda la línea costera, luego evoluciona hacia la Sierra por Cajamarca y Junín, penetrando finalmente en la Selva peruana hasta Loreto y San Martín y a muchos otros países del continente americano (4). Los esfuerzos del Ministerio de Salud fueron dedicados, los primeros meses, al fortalecimiento del manejo de la deshidratación. Esto se tradujo en que el Perú presentó muy bajas tasas de letalidad por cólera, lo cual fue reconocido en el ámbito internacional (4).

A fines de 1991 se habían reportado más de 391220 casos de cólera en 16 países del continente americano, siendo los más afectados Perú, Ecuador y Colombia, dando cuenta del 97\% del total de casos de la región. Durante 1992 y 1993, el cólera epidémico continúo transmitiéndose en forma intensa en el continente Americano (4).

El Perú era un país a merced de los grupos subversivos, saliendo de una hiperinflación terrible y sin reservas. Ahora en cambio, somos un país con economía estable, con reservas importantes que puede enfrentar con éxito las etapas iniciales de la pandemia.

¿Que nos puede traer la pandemia? La pandemia de hecho producirá efectos negativos, pero también puede tener efectos positivos, puede generar situaciones directamente relacionadas con la propia pandemia y otras relacionadas con las acciones que tomen los gobiernos.

El impacto en la economía del país, de las instituciones, empresas y de las familias, es evidente lo que no sabemos es la magnitud. Como en la epidemia de cólera, el país incurrirá en gastos no planeados en materiales, equipos e infraestructura.

Debido a que todas las acciones dispuestas por los gobiernos están dirigidas a la prevención de la propagación del virus y al tratamiento de los infectados con el covid-19, destinando la infraestructura y recursos humanos de los servicios de salud, el control de los pacientes con enfermedades crónicas no transmisibles, no será del todo adecuado y no podemos predecir sus consecuencias.

Además, se pueden generar problemas derivados de las medidas dispuestas por los gobiernos, por ejemplo, por el aislamiento social (cuarentena) y los problemas ergonómicos por el trabajo remoto. En este fascículo se publica un ensayo sobre los efectos psicológicos de la cuarentena en la pandemia. 
La investigación en el mundo y en los siguientes meses estará enfocada en asuntos relacionados con el covid-19 y con el virus SARS-CoV-2. Por ello, se espera en los siguientes meses publicaciones de diversas áreas de la ciencia relacionadas con la pandemia.

Juan Miyahira ${ }^{1}$

\section{REFERENCIAS BIBLIOGRÁFICAS}

1. Organización Mundial de la Salud. Alocución de apertura del Director General de la OMS en la rueda de prensa sobre la COVID-19 celebrada el 11 de marzo de 2020. Ginebra: Organización Mundial de la Salud; 2020. (Citado el 15 de abril del 2020). Disponible en: https://www.who.int/es/ $\mathrm{dg} / \mathrm{speeches/detail/who-director-general-s-}$ opening-remarks-at-the-media-briefing-on-covid19---11-march-2020

2. Presidencia de la República del Perú. Decreto Supremo que declara en Emergencia Sanitaria a nivel nacional por el plazo de noventa (90) días calendario y dicta medidas de prevención y control del COVID-19. Decreto Supremo N ${ }^{\circ}$ 008-2020SA. El Peruano. 11 de marzo de 2020. Disponible en: https://busquedas.elperuano.pe/normaslegales/ decreto-supremo-que-declara-en-emergencia- sanitaria-a-nivel-decreto-supremo-n-008-2020sa-1863981-2/

3. Presidencia del Consejo de Ministros. Decreto Supremo que declara estado de Emergencia Nacional por las graves circunstancias que afectan la vida de la Nación a consecuencia del brote del COVID-19. Decreto Supremo No 044-2020-PCM. El Peruano. 15 de marzo de 2020. Disponible en: https://busquedas.elperuano.pe/normaslegales/ decreto-supremo-que-declara-estado-deemergencia-nacional-po-decreto-supremo-n-0442020-pcm-1864948-2/

4. FAO/OMS. Experiencia de la epidemia del cólera en el Perú 1991. Foro Mundial FAO/OMS de Autoridades Sobre Inocuidad De los Alimentos Marrakech, Marruecos 28 - 30 de enero de 2002. Disponible en: http://www.fao.org/3/ab416s/ ab416s.htm\#: : text=E1\%20a\%C3\%B1 o\%20 $1991 \% 20$ el\%20pa\%C3\%ADs, costeras\%20 Chancay $\% 2 \mathrm{C} \% 20$ Chimbote $\% 20 \mathrm{y} \% 20$ Piura. 